\title{
INTUSSUSCEPTION DUE TO ENTRAPPED ASCARIS: AN ULTRASOUND CASE REPORT
}

\author{
Prashant U. Titare ${ }^{1}$, Bhawana D. Sonawane ${ }^{2}$, Pradip B. Rathod ${ }^{3}$, Narendra G. Tembhekar ${ }^{4}$
}

\section{HOW TO CITE THIS ARTICLE:}

Prashant U. Titare, Bhawana D. Sonawane, Pradip B. Rathod, Narendra G. Tembhekar. "Intussusception Due to Entrapped Ascaris: An Ultrasound Case Report". Journal of Evolution of Medical and Dental Sciences 2014; Vol. 3, Issue 56, October 27; Page: 12848-12852, DOI: 10.14260/jemds/2014/3707

ABSTRACT: Intestinal intussusception caused by ascaris is uncommon. Abdominal ultrasound is generally done as a first imaging investigation for abdominal symptoms. This report described the ultrasound features in this rare case of adult intussusception due to entrapped ascaris, making a significant contribution to radiological knowledge in diagnosing the cause at the earliest for better management.

KEYWORDS: Ascaris, intussusception, ultrasound.

INTRODUCTION: Ascaris lumbricoides is the most common intestinal nematode affecting human beings. Approximately one fourth of the world population is estimated to be affected with ascariasis. Infestation could be silent or may lead to serious complications like intestinal obstruction, volvulus and intussusception. ${ }^{1}$ Ultrasound is noninvasive, quick, safe and easily available imaging modality can be used to diagnose intestinal worms. A case of intussusception with ascaris as leading point had been reported earlier.2 Prior to current report ultrasound features of intussusception due to entrapped ascaris have not been described in the world literature.

CASE HISTORY: A 25 year old schizophrenic female was referred from mental hospital to gastroenterology department of our hospital with history of vomiting since 2 day. Patient was irritable and crying. She was on antipsychotic medication since 10 years. On clinical examination, her vitals were stable. BMI was $16 \mathrm{~kg} / \mathrm{m} .{ }^{2}$ Cardiovascular, respiratory and neurological examination was normal. Abdominal examination revealed guarding in lower abdomen.

Her hemoglobin was $9.8 \mathrm{~g} / \mathrm{dl}$. Other routine blood investigations were within normal limit. Erect abdominal radiograph revealed multiple air fluid levels. Ultrasound in transverse scan revealed lower abdominal doughnut like bowel mass containing multiple target and rings like shadows between the inner and outer part of the mass Figure 1. Mass showed pseudokidney appearance on longitudinal scan. On Doppler examination flow was not visualized within the mass. Proximal small bowel loops were dilated Figure 2. Multiple curved or straight, long echogenic tubes with or without central anechoic tube were present within the bowel loops on longitudinal scan Figure 2 and giving ring like appearance on transverse scan Figure 3.

Diagnosis of intestinal obstruction due to intussusception with entrapment of worms between intussusceptum and intussuscipien was made. Emergency laparotomy was done which revealed irreducible ilioileal intussusception and presence of ascaris between the intussusceptum and intussuscipien with ischemic changes. Resection and anastomosis was done. Postoperatively piperazine was started and later on albendazole was prescribed. 


\section{CASE REPORT}

DISCUSSION: Telescoping of one bowel segment into lumen of the adjacent bowel segment represents an intussusception which appears as complex soft tissue mass consisting of the central intussusceptum and the outer intussuscipien. Intussusception is more commonly seen in children. Adult intussusception is an uncommon entity representing 5\% of all intussusceptions and $1 \%$ of all bowel obstructions. $90 \%$ of adult intussusceptions are caused by an underlying disorder like neoplasm and a postoperative conditions of which neoplasm contribute approximately $65 \%$ of all cases $^{3}$.

It is commonly believed that masses in the bowel acts as an irritant causing the abnormal peristaltic movement leading to an intussusception. It commonly present with abdominal pain, nausea, vomiting and less commonly as melena, weight loss, fever and constipation. ${ }^{3}$ Ascaris infestation is commonly observed in the underdeveloped countries like India. ${ }^{4}$ It is endemic in the areas with illiteracy, ignorance, poor hygiene, poverty and malnutrition. Frequency of disease distribution varies according to economic condition, culture, climate, region and latitude ${ }^{1}$.

Approximately 3 billion peoples in the world were reported to be infected by ascaris. It is prevalent in the tropical countries. Prevalence of approximate $45 \%$ had been reported in some regions of Asia and Latin America with approximate 1000000 new annual cases. Approximately 60000 annual deaths are attributed directly to ascariasis. It occurs in all age group but more commonly seen in children. ${ }^{4}$

Clinically it can be silent or lead to acute or chronic symptomatology. It may present with loss of weight, chronic abdominal pain, nausea, vomiting and passage of worms in the stool. Most commonly it present as chronic infestation which contributes to the malnutrition. Complications like intestinal obstruction, volvulus, intussusception, appendicitis, bowel perforation had been reported which need urgent expert attention. Infestation is acquired by ingestion of ascaris eggs. Larvae migrate to the lung and complete their maturation. Afterward they ascend into respiratory tract and by the process of swallowing migrate to the small intestine of the human being where they become adults. ${ }^{1}$

Ultrasound is a useful tool to diagnose the adult intestinal ascariasis, dilated bowel loops and sometimes in diagnosing the cause of obstruction. Ultrasound appearance of ascaris is reported in various studies as presence of long echogenic structure (linear or curved, single or multiple) with or without a central anechoic tube, mostly without acoustic shadowing.5,6,7 Varied appearances like "winding highway" or "parallel lines", "railway track"sign, "3 line" or "4 line" sign on longitudinal scan and doughnut or target sign, ring sign, bull's eye appearance on transverse scan had been reported in cases of ascariasis. $.5,7,8$

Ultrasound has high sensitivity (98-100\%) and specificity (88-100\%) for the diagnosis of intussusception. Doughnut sign had been reported commonly in intussusceptions in which hypoechoic outer ring is formed by the everted limb of the intussusceptum and the intussuscipien. Central part varies with the section level. Hypo-echoic Centre is generally seen at the apex portion of intussusceptions due to central limb of intussusceptum without mesentery. At the base of intussusceptions Centre is hyper-echoic crescent-shaped.It is seen when the mesentery enclosed the central limb of the intussusceptions (crescent in doughnut sign).

Sandwich sign, hayfork sign, pseudokidney sign can be seen on longitudinal scan. Three parallel hypo-echoic bands with interposing two hyper-echoic band gives sandwich sign. Outer two hypo-echoic bands represents edematous everted limb of intussusceptum and thin intussuscipien. 


\section{CASE REPORT}

Central hypo-echoic band represents central limb of intussusceptum. Hyper-echoic bands are due to enclosed mesentery. Hayfork sign is a variant of sandwich sign seen at apex where three hypo-echoic bands going to join. Pseudokidney sign seen in oblique scan or curved intussusceptions in which hyper-echoic mesentery seen on only one side of central limb of intussusceptum. ${ }^{9}$

The management of intestinal ascariasis is conservative unless there has any serious complications. ${ }^{5}$ Our patient had irreducible intussusceptions and underwent surgery for this. Such a type of ascaris presentation is uncommon and knowledge of ultrasound finding in such a case will definitely help the readers.

\section{REFERENCES:}

1. Galiano Gil J, Leyva Esturo C, Peña Ayala R. Intestinal Obstruction Due To Ascaris. The Internet Journal of Surgery.2005; 8(2):16.

2. Karatepe O, Tukenmez M, Hunerli K, Citlak G, Salmaslioglu A, Battal M et al. Ascaris as a leading point for small-bowel intussusceptions in an adult: a rare cause of intussusception. Am J Emerg Med.2008; 26(3): 381.e3-4.

3. Choi SH, Han JK, Kim SH, Lee JM, Lee KH, Kim YJ et al. Intussusception in Adults: From Stomach to Rectum AJR 2004; 183: 691-8.

4. Yetim I, Ozkan OV, Semerci E, Abanoz R. Rare cause of intestinal obstruction, Ascaris lumbricoides infestation: two case reports. CasesJournal2009; 2: 7970.

5. Sharma UK. Efficacy of Ultrasonography in Detecting Intestinal and Biliary Ascariasis. Health Renaissance 2011; 9 (1):3-6.

6. Schulman A, Laxton AJ, Heydenrych JJ, Abdurahman KE. Sonographic diagnosis of biliary ascariasis. AJR1982; 139: 485-9.

7. Goyal A, Gamanagatti S, Sriram J. Tube within Tube: Ascaris in Bowel and Biliary-Tract. Am J Trop Med Hyg. 2010; 83(5): 962.

8. Mehta V, Goyal S, Pandit S, Mittal A, Aggarwal A. Sonographic Diagnosis of Ascaris lumbricoides Infestation as a cause of Intestinal Obstruction. Indian Journal of Pediatrics2010; 77: 827.

9. Del-Pozo G, Albillos JC, Tejedor D, Calero R, Rasero M, De-la-Calle U et al. Intussusception in children: Current concepts in diagnosis and enema reduction. Radiographics1999; 19: 299-319. 


\section{CASE REPORT}

Figure 1: Ultrasound image (Transverse scan) at apex (A) and middle (B \& C) level of intussusceptions showing doughnut like appearing bowel mass Intussusception containing multiple target and ring like shadows of entrapped ascaris worm (represented by arrow) between intussusceptum and intussusception.

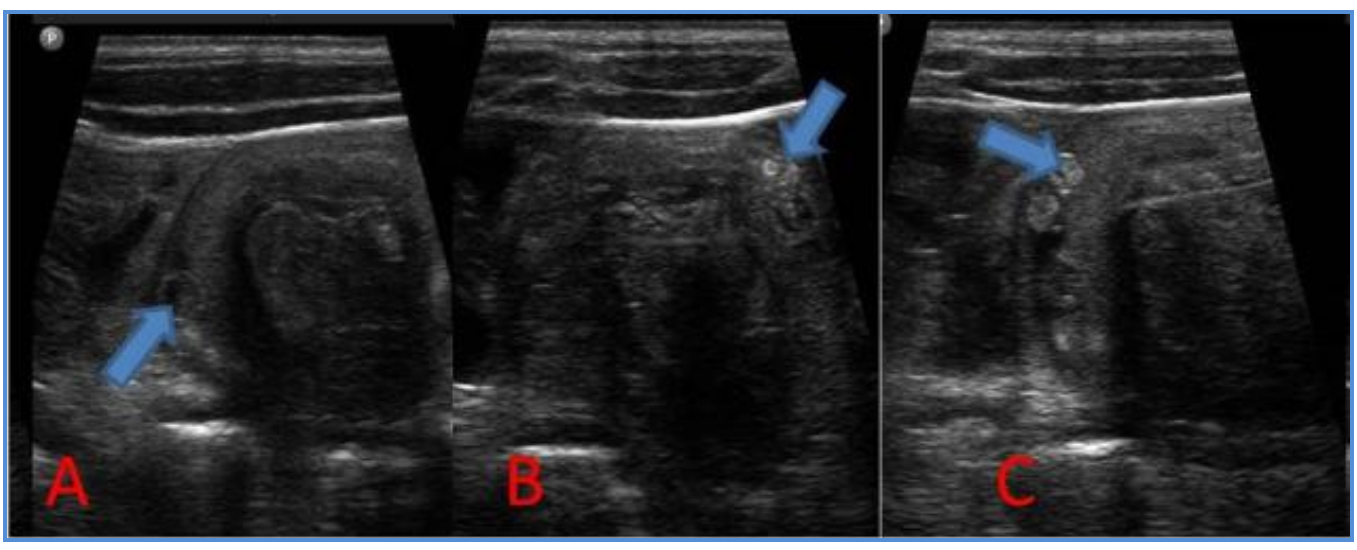

\section{Figure 1}

Figure 2: Ultrasound image (Longitudinal scan) showing ascaris as a long, curved echogenic tube (represented by arrow) within the dilated small bowel loop proximal to intussusception.

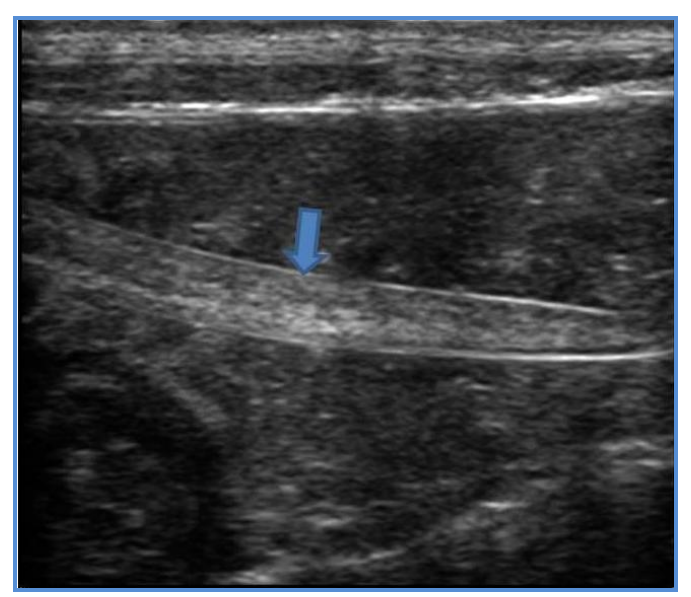

Figure 2 


\section{CASE REPORT}

Figure 3: Ultrasound image (Transverse scan) showing ascaris as multiple ring like shadows (represented by arrow) within the collapsed small bowel loop distal to intussusception.

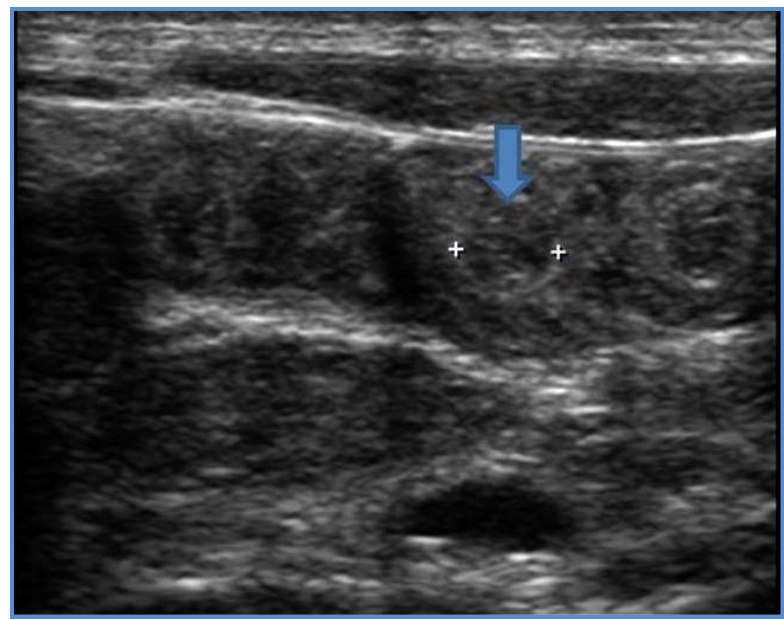

Figure 3

\section{AUTHORS:}

1. Prashant U. Titare

2. Bhawana D. Sonawane

3. Pradip B. Rathod

4. Narendra G. Tembhekar

\section{PARTICULARS OF CONTRIBUTORS:}

1. Assistant Professor, Department of Radiology, Government Medical College and Super speciality Hospital, Nagpur, Maharashtra, India.

2. Professor, Department of Radiology, Government Medical College and Super speciality Hospital, Nagpur, Maharashtra, India.

3. Assistant Professor, Department of Radiology, Government Medical College and Super speciality Hospital, Nagpur, Maharashtra, India.
4. Associate Professor, Department of Radiology, Government Medical College and Super speciality Hospital, Nagpur, Maharashtra, India.

\section{NAME ADDRESS EMAIL ID OF THE CORRESPONDING AUTHOR:}

Dr. Prashant Uddhaorao Titare, C/0 M. G. Dahat, Plot No. 60, Newindira Colony, Bhagwan Nagar, Nagpur, Maharashtra, India.

Email: putitare@gmail.com

Date of Submission: 09/10/2014.

Date of Peer Review: 10/10/2014.

Date of Acceptance: 22/10/2014.

Date of Publishing: 27/10/2014. 